\title{
Cytotoxicity of components of resins and other dental restorative materials
}

\author{
J.C. WATAHA, C.T. HANKS, S.E. STRAWN and J.C. FAT The \\ University of Michigan School of Dentistry, Ann Arbor, MI, U.S.A.
}

\section{Summary}

Cytotoxicity testing of dental restorative materials must be viewed as an assessment of hazards, that is the potential of the material to cause pulpal problems. In this context, composites, glass ionomers, amalgams, zinc-based cements and peroxide bleaching agents are all possible hazards to the pulp. The risks that these materials will cause pulpal toxicity in vivo can be partly estimated by assessing the cytotoxicity of the substances which are released from these materials in vitro and comparing these cytotoxic concentrations with those concentrations that are present in vivo. The resin components of composites, metal ions and hydrogen peroxide, all of which are released from dental restorative materials, have been shown to be cytotoxic in vitro in sufficient concentrations. The potencies of these substances are quite diverse. However, the cytotoxicity of these substances in usage tests, and therefore the risks of pulpal toxicity, depends on their ability to diffuse through the dentine and accumulate in the pulp.

\section{Introduction}

The testing of the cytotoxicity of restorative dental materials is important from two standpoints. First, cytotoxicity tests have become an accepted means of screening dental materials for biocompatibility (ADA, 1979; ANSI/ADA, 1982). The improvement of these tests should ultimately provide a more accurate means to screen new materials and reduce the need for animal or human testing. Second, the interaction of materials and the components of materials with cells at the molecular level are probably responsible for tissue-level reactions such as inflammation, necrosis, immunogenesis and carcinogenesis (Hodgson \& Levi, 1987; Costa, 1991). Understanding these material-cell interactions is a necessary precursor to understanding the way materials elicit their in vivo responses.

The concepts of hazards and risks are central to interpreting cytotoxicity tests (Clarkson, 1992). A material is hazardous if it has the potential to cause a problem when placed into the body. Hazardous materials are generally identified through screening tests which place a material in direct contact with either cultured cells or animal tissues, although the material will generally not be placed in the context of its intended use. Risk, on the other hand, is the likelihood that problems will occur when a material is put into use. It is important to understand that a material which is hazardous may not pose a significant risk to the body. The risk may be reduced 
because of diffusion or dilution of the offending components, biological barriers, or a lack of sufficient time of contact between the offending components and susceptible tissues. Although cytotoxicity tests have beeen used for many years to assess how hazardous a material might be, it is the goal of many in vitro testing models to be able to define, or at least partially define, the risks these materials may pose before they are put into the body.

Historically, many types of tooth restorative materials have been determined to be hazards. For example, Hume \& Mount (1988) determined that glass ionomer cements were toxic when in direct contact with L929 fibroblasts. Müller et al. (1990) found that some glass ionomer cements were also toxic to primary rabbit pulpal fibroblasts. Helgeland \& Leirskar (1972) demonstrated that both high- and low-copper amalgams were toxic in vitro, and Leirskar (1974) later showed that metal ions released from these amalgams were probably responsible for these reactions. Kaga et al. (1988) more recently showed that both whole amalgams and their phases were cytotoxic. Hanks, Anderson \& Craig (1981) and Meryon \& Riches (1982) both found that composite materials were cytotoxic to fibroblasts and macrophages. Finally, Kawahara, Yamagami \& Nakamura (1968) showed that silicate and zinc phosphate cements were toxic to cultured cells, especially early in the setting process.

Several researchers have shown that hazard tests are not necessarily good indicators of in vivo biocompatibility, and that these tests may yield conflicting results even among themselves. Hensten-Pettersen \& Helgeland (1977) found that silicate cement, zinc-oxide eugenol cement and composite elicited different responses in four different direct-contact cell-culture tests. Mjör, Hensten-Pettersen \& Skogedal (1977) later showed that cell-culture tests on these materials did not agree with implantation or pulpal (usage) tests. In another study, Spångberg (1978) reached a similar conclusion. These types of studies reinforce the danger of using tests which measure hazards to predict the performance of dental restorative materials in vivo.

Two strategies have been used to try to identify the risks associated with dental restorative materials by means of in vitro tests. The first strategy is to test the toxicity of the components of a material to cells in monolayer culture, then measure the concentrations of those components which exist in vivo. Since individual components are used, dose-response curves can be determined in vitro and the cytotoxic potential of the in vivo concentrations can then be estimated. The duration of the exposure and synergism or antagonism between components can also be tested in this manner. The second strategy is to use barriers between the material and the cells, to mimic barriers which might exist in vivo. For pulpal effects, dentine barriers have been used (Tyas, 1977; Meryon \& Riches, 1982; Hume, 1984; Hanks et al., 1987; Hanks et al., 1989; Li et al., 1992; Schmalz \& v. Gymnich, 1993). This strategy has been somewhat successful in assessing in vivo risks with in vitro systems. More recent investigations have combined these two strategies by testing the components of a material through a dentine barrier thereby helping to identify which components might be responsible for pulpal effects through dentine or substances which mollify those effects by reducing dentine permeability (Pashley, 1985; Hanks et al., 1989; Gerzina \& Hume, 1993).

The remainder of this paper will address the cytotoxicity of resins, metal ions and hydrogen peroxide. These components are known to be released from dental restorative or treatment materials and therefore are potentially hazardous to pulpal tissues. Ferracane \& Condon (1990), among others, have shown that resin composites release components immediately after placement. Leirskar (1974) and Okabe et al. 
(1987) have documented the release of metal ions from amalgams, and Hanks et al. (1993) have shown that a number of bleaching agents release hydrogen peroxide.

\section{Cytotoxicity of resins}

Hazard testing of a number of components of resin composites was reported by Hanks et al. in 1991. These investigators tested the cytotoxicity of 11 components toward Balb/c 3T3 mouse fibroblasts. Figure 1(a) shows the response of DNA synthesis of these cells toward Bis-GMA over a $24 \mathrm{~h}$ period. The Bis-GMA resin was added to the culture at time zero. With concentrations of $5 \mu \mathrm{mol} / 1$, a depression of DNA synthesis was apparent at $8 \mathrm{~h}$, and the toxic effect increased as time progressed to $24 \mathrm{~h}$. The first evidence of cytotoxicity occurred at a concentration between 0.5 and $5 \mu \mathrm{mol} / \mathrm{l}$.

These authors reported that the potencies of the resin components varied by greater than 100 times. Figure 2 summarizes the concentrations of four of these components which cause a $50 \%$ decrease in cellular activity (TC50 concentration). The TC50 concentration is commonly used in toxicology to measure the toxic response, and the potency of the cytotoxic response is inversely proportional to the TC50 concentration. Thus, a chemical which has a low TC50 concentration is defined as having a high potency. Given these definitions, Fig. 2 shows that the primary components of resin

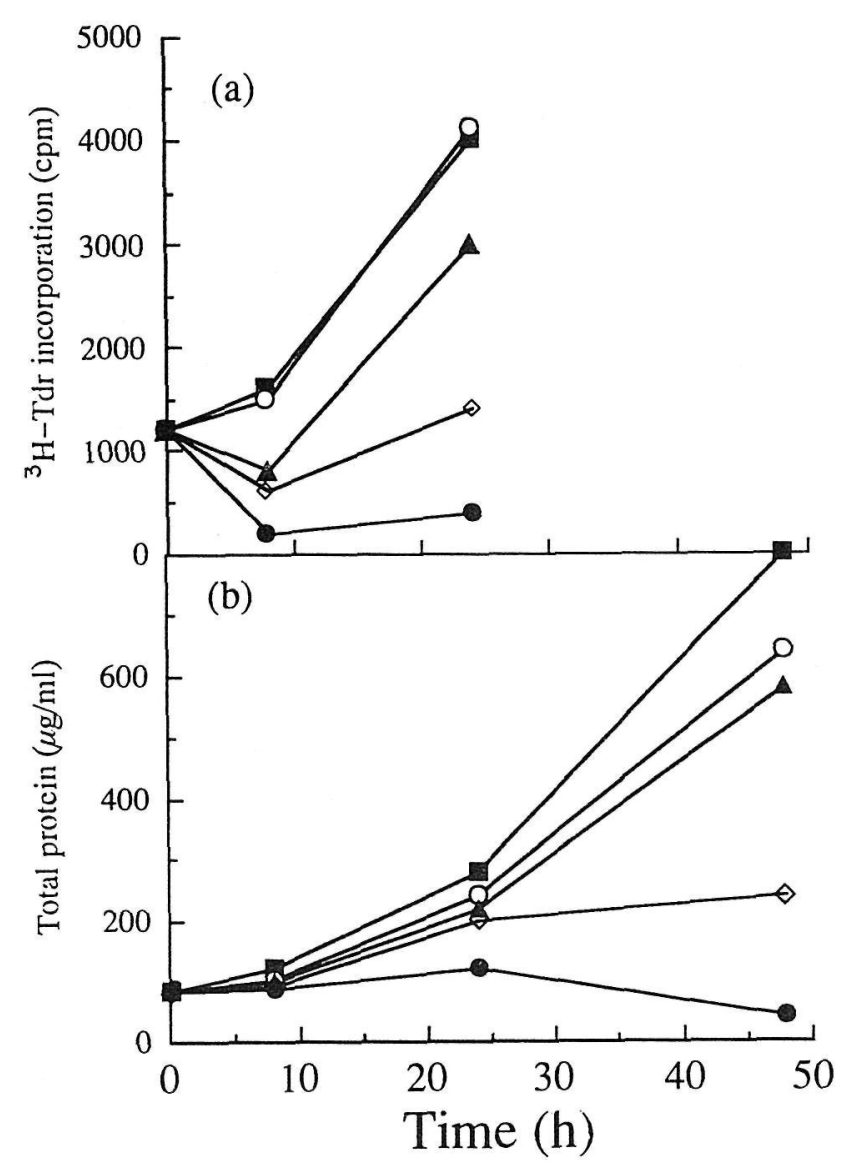

Fig. 1. (a) Bis-GMA which was added to a culture of Balb/c 3T3 mouse fibroblasts at time zero produced a depression in the incorporation of tritiated thymidine $(3 \mathrm{H}-\mathrm{Tdr}$, approximating DNA synthesis) between 0.5 and $5 \mu \mathrm{mol} / 1$. The effect was apparent $8 \mathrm{~h}$ after addition of the resin and became more pronounced at $24 \mathrm{~h}$, especially at concentrations above $5 \mu \mathrm{mol} / \mathrm{l}$. (b) Bis-GMA was added to cultures as in (a), but was removed from the culture medium at $24 \mathrm{~h}$. The total protein in the monolayer (approximating cell number) was irreversibly suppressed above $10 \mu \mathrm{mol} / 1$. $5 \mu \mathrm{mol} / 1 ; \bullet, 25 \mu \mathrm{mol} / \mathrm{l} ; \circ, 0.5 \mu \mathrm{mol} / 1 ; \diamond 10 \mu \mathrm{mol} / 1$. 


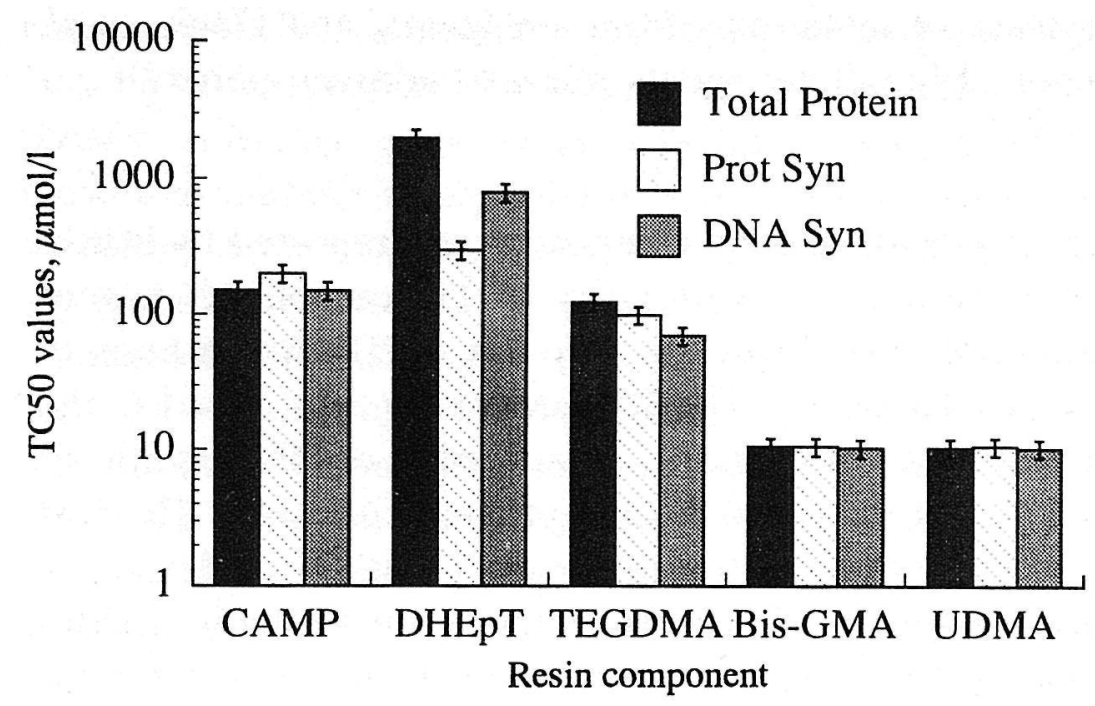

Fig. 2. A comparison of the potencies of five common components of a restorative resin system. Camphoroquinone (CAMP) is a light activated initiator, N,N-dihydroxyethy-p-toluidine (DHEpT) is an accelerator, triethyleneglycol dimethacrylate (TEGDMA) is a diluent, and bis glycidyl methacrylate (Bis-GMA) and urethane dimethacrylate (UDMA) are oligomers. These components were added to cultured Balb/c $3 \mathrm{~T} 3$ fibroblasts for $24 \mathrm{~h}$, and their effects on total protein, protein synthesis and DNA synthesis were measured. The $y$-values are the concentrations of these compounds which suppressed cell activity by $50 \%$. It is apparent that these compounds have diverse potencies.

composites varied in their potency and that total protein, protein synthesis and DNA synthesis were roughly equivalent in measuring these potencies for most components.

Hanks et al. (1991) also measured the reversibility of the toxic effects by removing the resins from the cell-culture medium and allowing the culture to recover for an additional $24 \mathrm{~h}$. Figure 1(b) illustrates the results of this type of experiment for Bis-GMA using $\mathrm{Balb} / \mathrm{c}$ fibroblasts and measuring the total protein present in the cell-culture. The Bis-GMA was removed from the culture system at $24 \mathrm{~h}$. Thus, the period between 24 and 48 h shows the reversibility of the toxic response. For Bis-GMA concentrations between 5 and $10 \mu \mathrm{mol} / 1$, the cell-cultures appeared to lose their ability to recover. In general, the concentrations of resins above which no reversibility was seen was of the same magnitude as the TC50 values.

In summary, the components of resin composites are hazardous in that they all cause significant toxicity in direct contact with fibroblasts. However, these components have diverse potencies and the risks that they pose to the dental pulp depend upon the quantities which permeate the dentine and accumulate in the pulp.

\section{Cytotoxicity of metal ions}

Several dental restorative materials release metal ions which may be hazardous to pulpal tissues. These include ions of $\mathrm{Ag}, \mathrm{Cu}, \mathrm{Hg}$ (released from amalgams), $\mathrm{Al}$ (released from glass ionomer cements), and $\mathrm{Zn}$ (released from several types of cements). The cytotoxicity of these metal ions have been studied by a number of investigators, but the diversity of the methods used make direct comparisons difficult. This discussion will focus on a few representative investigations and compare the results.

Leirskar (1974) used NCTC epithelial cells to measure the cytotoxicity of ions of $\mathrm{Ag}, \mathrm{Hg}, \mathrm{Cu}$ and $\mathrm{Zn}$ in an effort to discover which elements might be responsible for amalgam toxicity in vitro. TC50 concentrations were measured by counting the number of cells which remained after $24 \mathrm{~h}$ of exposure to these ions. Babich, Shopsis 
$\&$ Borenfreund (1986) used two fish cell-lines to study the toxicity of ions of $\mathrm{Cu}$ and $\mathrm{Zn}$, among others. These investigators measured cytotoxicity by neutral red uptake after cells were exposed to these meals for $24 \mathrm{~h}$. Neutral red is a dye which is taken up and retained only by viable cells. Thus, its uptake can be used to assess the number of viable cells after exposure to a substance. Wataha, Hanks \& Craig (1991) used Balb/c $3 \mathrm{~T} 3$ fibroblasts to assess the cytotoxicity of ions of $\mathrm{Ag}, \mathrm{Al}, \mathrm{Cu}$ and $\mathrm{Zn}$, among others. They measured cytotoxicity through the activity of a mitochondrial enzyme (succinic deydrogenase).

A comparison of these three investigations shows a remarkable level of agreement in the potency of these metal ions, considering the diverse cell lines and methods of measuring toxicity (Fig. 3). The potency of these metal ions ranged from $15 \mu \mathrm{mol} / 1$ for $\mathrm{Zn}^{+2}$ to almost $3000 \mu \mathrm{mol} / 1$ for $\mathrm{Al}^{+3}$. Differences in sensitivities of cell lines to dental materials have been reported previously (Babich et al., 1986, Hanks et al., 1981) and Wataha et al. (1991), among others have shown that different methods of measuring cytotoxicity affect the assessment.

The in vitro duration of the exposure of metal ions to cells has been shown to be a factor in affecting the apparent toxicity of metal ions (Wataha, Hanks \& Craig, 1992). An example of this effect is shown in Fig. 4 for $\mathrm{Cu}^{+2}$. The TC50 values for $\mathrm{Cu}^{+2}$ exposure to Balb/c 3T3 fibroblasts were plotted vs. the duration of exposure. For $\mathrm{Cu}^{+2}$, the TC50 was dramatically reduced as the duration of exposure increased, dropping 15 -fold over a $72 \mathrm{~h}$ period. This effect was larger than that seen for other metal ions or for Bis-GMA (Fig. 1(a)). The duration of exposure effect is important for in vitro testing, but may also be important in vivo if the exposure of pulpal tissues to these substances is extended.

The synergistic or antagonistic effects of two metal ions has also been investigated by Wataha et al. (1992). By assuming that the cytotoxic effects of two ions should be

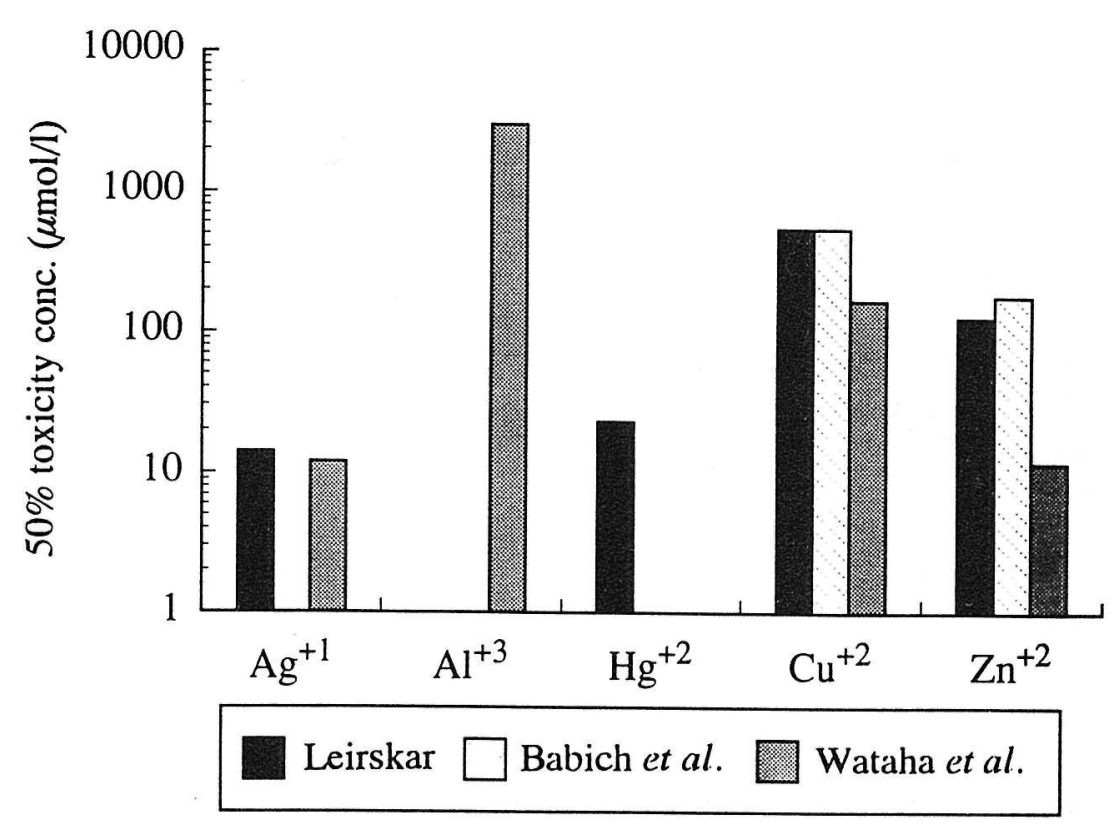

Fig. 3. A comparison of the concentrations of $\mathrm{Ag}^{+1}, \mathrm{Al}^{+3}, \mathrm{Hg}^{+2}, \mathrm{Cu}^{+2}$ and $\mathrm{Zn}^{+2}$ required to suppress cell activity by $50 \%$. Three studies are shown: Leirskar (1974); Babich, Shopsis \& Borenfreund (1986); and Wataha, Hanks \& Craig (1991). The potencies of these metal cations are diverse. The results of the three studies are remarkably similar considering the many variables inherent in the cellculture experiments. 


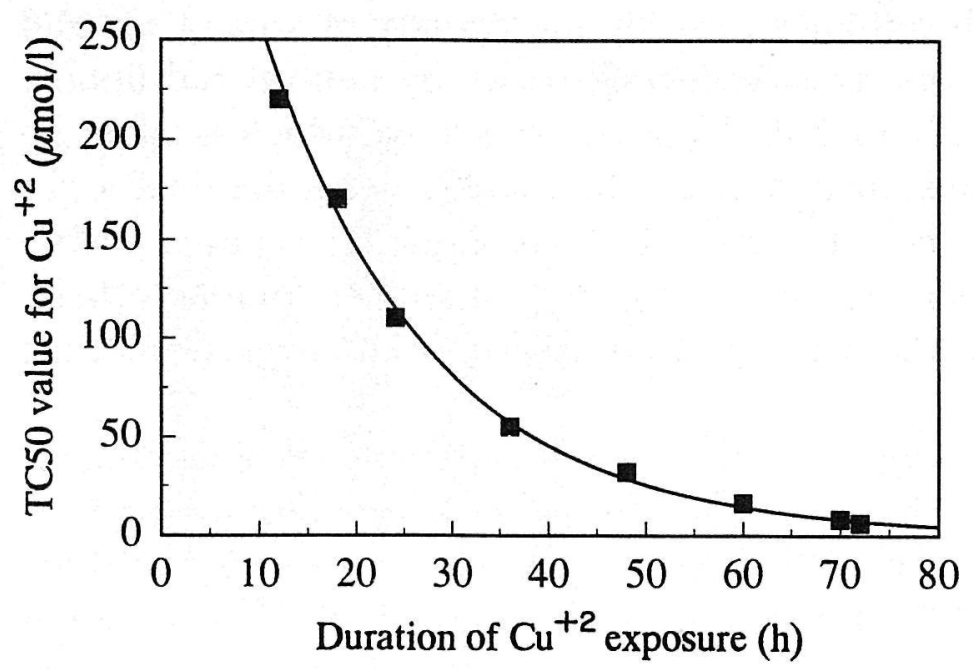

Fig. 4. The effect of duration of exposure on the potency of $\mathrm{Cu}^{+2}$ toward Balb/c $3 \mathrm{~T} 3$ fibroblasts. The $\mathrm{R}^{2}$ value for the least squares best fit curve is 0.99 . For short durations of exposure, the amount of $\mathrm{Cu}^{+2}$ required to reduce the succinic dehydrogenase activity of these cells by $50 \%$ (TC50 concentration) was above $200 \mu \mathrm{mol} / 1$. As the duration of exposure lengthened to $72 \mathrm{~h}$, the TC50 concentration dropped to less than $25 \mu \mathrm{mol} / \mathrm{l}$.

additive in the absence of synergistic or antagonistic effects, they have quantified these effects for several binary metal systems in vitro. These results for the $\mathrm{Ag}-\mathrm{Cu}$ system are shown in Fig. 5. Since the $z$-axis is the difference between the observed and expected succinic dehydrogenase activity in the presence of these ions, positive results indicate that there was a greater observed enzymatic activity than expected. This is interpreted as an antagonism of the cytotoxic effects of these ions, since an additive effect of the two cytotoxicities would have given a value with $z=0$. The presence of these types of effects was suggested in 1981 by Leirskar \& Helgeland. This subject has also been extensively reviewed by Magos (1981).

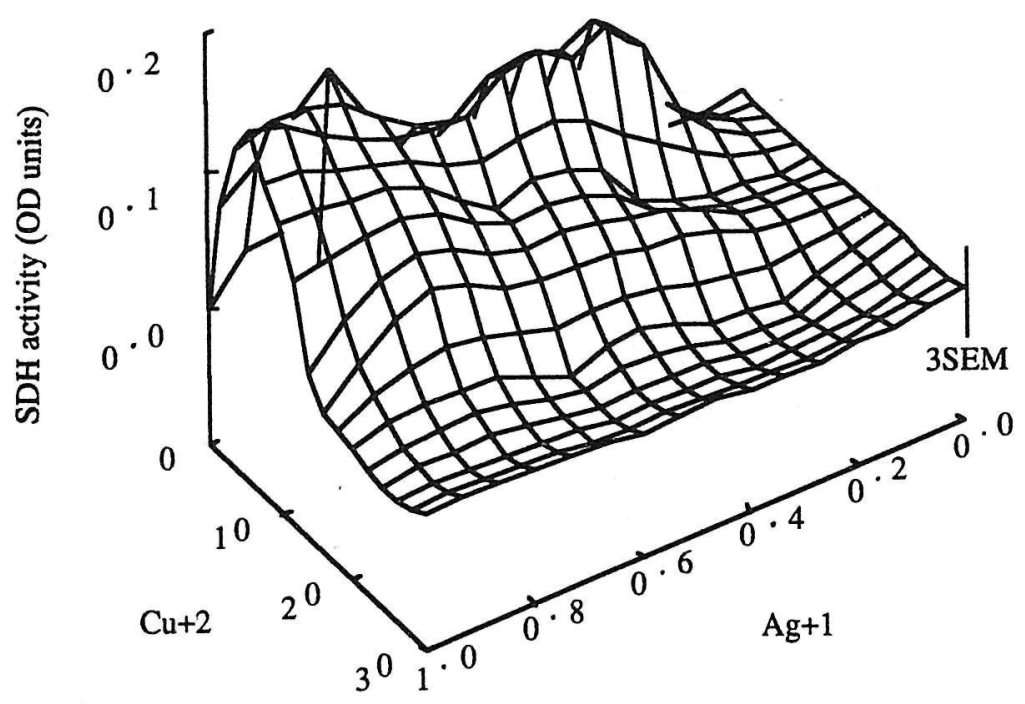

Fig. 5. The apparent antagonism of toxicity produced by concurrent exposure of Balb/c $3 T 3$ fibroblasts to $\mathrm{Ag}^{+1}$ and $\mathrm{Cu}^{+2}$. The $z$-axis shows the difference between the observed and expected succinic dehydrogenase (SDH) activity, a measure of mitochondrial function measured by the conversion of tetrazolium dye to its formazan salt. The $x$ and $y$ axes are the concentrations of $\mathrm{Cu}^{+2}$ and $\mathrm{Ag}^{+1}$ in $\mu \mathrm{g} / \mathrm{ml}$, respectively. The error bar is three standard deviations of the mean (3SEM). This surface indicates antagonism of the toxic effect because the SDH activity was greater than expected $(>0)$ assuming that toxicity of the $\mathrm{Ag}^{+1}$ and $\mathrm{Cu}^{+2}$ were independent and additive. 
In summary, metal ions which have the potential to be exposed to the dental pulp are hazards. As with the resin materials, the potencies of these ions are diverse and the risks which these components pose to the pulp are dependent upon the concentrations which reach the pulp via diffusion through dentine.

\section{Cytotoxicity of hydrogen peroxide}

A number of investigators hare worked in this area, but recent data which assessed the cytotoxicity of hydrogen peroxide in a dental context has been reported by Hanks et al. (1994). These investigators reported that the TC50 values for hydrogen peroxide was $880 \mu \mathrm{mol} / 1$ after $1 \mathrm{~h}$ of exposure to Balb/c 3T3 cells and only $300 \mu \mathrm{mol} / 1$ after a $6 \mathrm{~h}$ exposure. Considering the relatively short durations of exposure, hydrogen peroxide would seem to be a definite hazard if exposed to pulpal tissues.

The effect of several bleaching agents on cellular metabolism has also been reported (Hanks et al., 1994). These investigators first determined the potency of $\mathrm{H}_{2} \mathrm{O}_{2}$ in direct contact with cells in vitro. The results are shown in Fig. 6, with the small dark squares representing the succinic dehydrogenase activity of Balb/c 3T3 fibroblasts relative to the negative control. The regression line is a best-fit curve of these points. The cytotoxicity of various bleaching agents were then tested through dentine disks, with the bleaching agent on one side of the disk and cell-culture medium on the puplal side of the disk. The culture medium was left in contact with the disks for $1 \mathrm{~h}$, after which its $\mathrm{H}_{2} \mathrm{O}_{2}$ content and cytotoxic effect were measured. The effects of cell-culture medium on succinic dehydrogenase activity were then plotted on the same graph as the $\mathrm{H}_{2} \mathrm{O}_{2}$ dose-response curve (Fig. 6). It is evident that the cytotoxic effects of the pulpal extracts of the bleaching agents corresponded closely to the cytotoxic effects of an equivalent dose of pure $\mathrm{H}_{2} \mathrm{O}_{2}$. The authors concluded that the cytotoxic effects of the bleaching agents in this system were primarily caused by diffusion of $\mathrm{H}_{2} \mathrm{O}_{2}$ through the dentine. This study seems to establish that $\mathrm{H}_{2} \mathrm{O}_{2}$ is not only a hazard, but also a risk to pulpal tissues if in contact with permeable dentine.

\section{Conclusions}

Table 1 summarizes the potencies of the substances presented in this paper. All substances were exposed to cells for $24 \mathrm{~h}$ except hydrogen peroxide, which was exposed

Table 1. Comparison of $50 \%$ toxicity concentrations (TC50s) for resin components, metal ions and hydrogen peroxide after $24 \mathrm{~h}$ exposure

\begin{tabular}{lc}
\hline Substance & TC50 Value $(\mu \mathrm{mol} / \mathrm{l})$ \\
\hline Bis-GMA & $10 \cdot 5$ \\
UDMA & $10 \cdot 3$ \\
TEGDMA & 100 \\
CAMP & 150 \\
DHEpT & 900 \\
$\mathrm{Ag}^{+1}$ & 14 \\
$\mathrm{Al}^{+3}$ & 3000 \\
$\mathrm{Cu}^{+2}$ & $160-400$ \\
$\mathrm{Hg}^{+2}$ & 25 \\
$\mathrm{Zn}^{+2}$ & $15-180$ \\
$\mathrm{Hydrogen}$ peroxide & $<300^{*}$ \\
\hline
\end{tabular}

* Duration of exposure $=6 \mathrm{~h}$. 


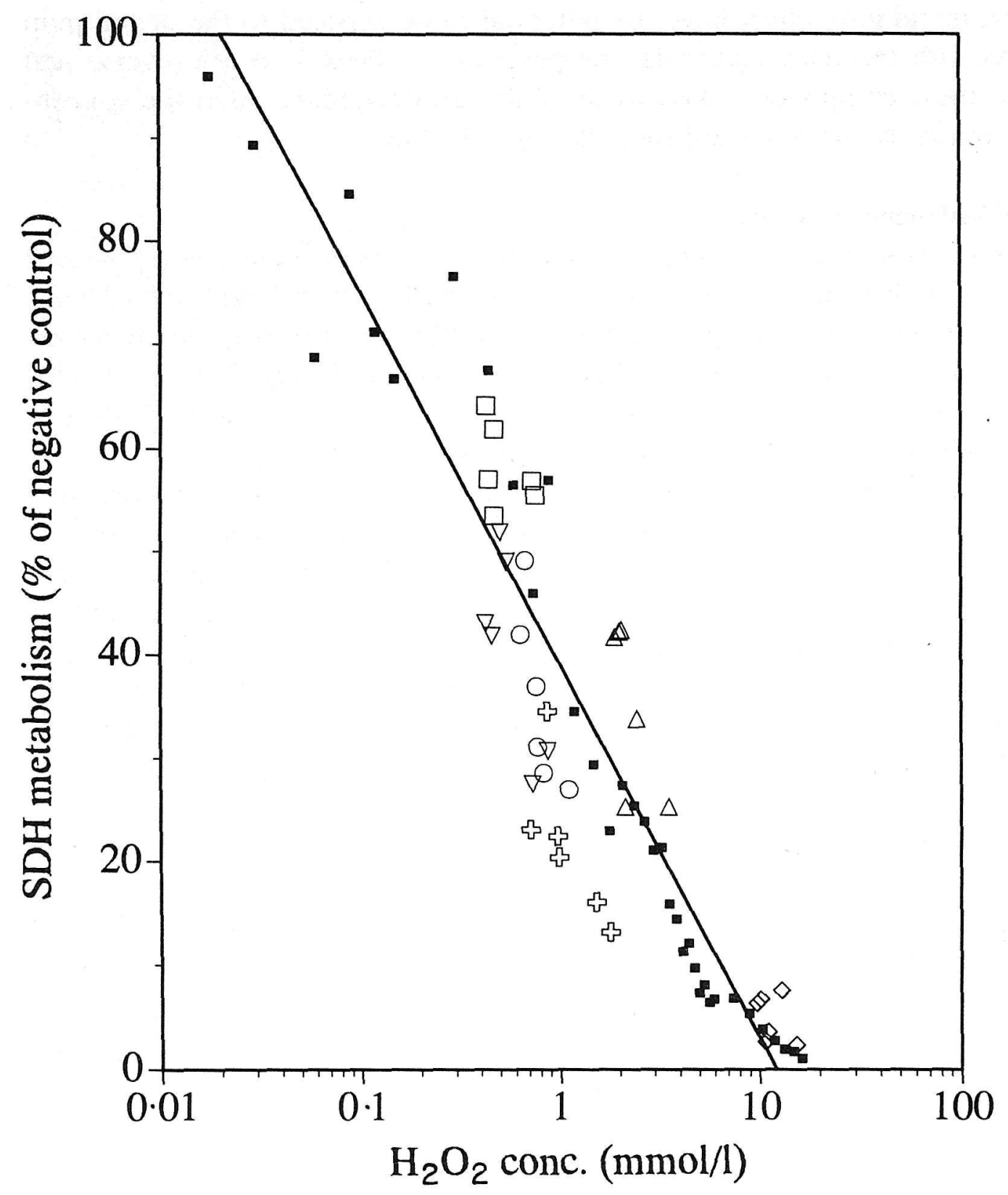

Fig. 6. The effect of extracts of bleaching agents on Balb/c $3 T 3$ succinic dehydrogenase metabolism after $1 \mathrm{~h}$ of exposure. The bleaching agents were extracted through dentine disks into cell-culture medium for $1 \mathrm{~h}$. The extracts were then evaluated for cytotoxicity. The cytotoxicity of the extracts (open symbols) corresponds closely with the cytotoxicity of pure hydrogen peroxide which was placed in direct contact with the fibroblasts ( and regression line). The authors concluded that the cytotoxicity of the bleaching agents was primarily caused by $\mathrm{H}_{2} \mathrm{O}_{2}$. (Figure adapted from Hanks et al., 1993).

for $6 \mathrm{~h}$. These substances have a wide range of potencies and because they are all toxic to cells some concentration, all are hazards to pulpal tissues by definition. However, in the absence of some reference material, it is difficult to put the potencies of these materials into perspective. In 1989, Hanks et al. proposed that phenol be used as a standard positive control for in vitro cytotoxicity testing. They tested the effect of phenol on the protein synthesis of Balb/c $3 \mathrm{~T} 3$ fibriblasts after a $24 \mathrm{~h}$ exposure. The $50 \%$ cytotoxicity concentration of phenol was $5000 \mu \mathrm{mol} / \mathrm{l}$. If the potencies of the substances in Table 1 are compared to the potency of phenol, then all of these substances appear to be of significant potency, with some metal ions and Bis-GMA being most outstanding in this respect. In spite of their apparent high toxic potency, the risk that these substances, or the materials they came from, pose a threat to the dental pulp 
depends on the concentrations of these substances which are released, the permeability of these substances through dentine, and the durations of exposure of the substances to pulpal cells. Furthermore, given the synergism and antagonism observed with some metal ions, these phenomena should not be ruled out for other components of materials. Estimation of the risks that pulpal tissues are affected by restorative dental materials is a complex process which is ultimately determined by putting the material into use. However, recent advances in cytotoxicity testing have begun to provide a means by which these risks can be partly estimated in vitro.

\section{Acknowledgments}

The authors thank the National Institutes of Health for support of this work through grant DE09296.

\section{References}

ADA (1979) American National Standards/American Dental Association Document No. 41 for recommended standard practices for biological evaluation of dental materials. Journal of the American Dental Association, 99, 697.

ANSI/ADA (1982) Addendum to American National Standards Institute/American Dental Association Document No. 41 for recommended standard practices for biological evaluation of dental materials, p. 10. American Nationl Standards Institute, New York.

Babich, H., Shopsis, C. \& Borenfreund, E. (1986) In vitro cytotoxicity testing of aquatic pollutants (cadmium, copper, zinc, nickel) using established fish cell lines. Ecotoxicology and Environmental Safety, 11, 91.

Clarkson, T.W. (1992) Principles of risk assessment. Advances in Dental Research, 6, 22.

Costa, M. (1991) Molecular mechanisms of nickel carcinogenesis. Annual Review of Pharmacology and Toxicology, 31, 321.

Ferracane, J.L. \& Condon, J.R. (1990) Rate of elution of leachable components from composite. Dental Materials, 6, 282.

GerzinA, T.M. \& Hume, W.R. (1993) TEGDMA elution from resin composites through dentin in vitro. Journal of Dental Research, 73(SI), 162, (Abstract No. 468).

Hanks, C.T., Anderson, M. \& Craig, R.G. (1981) Cytotoxic effects of dental cements on two cell culture systems. Journal of Oral Pathology, 10, 101.

Hanks, C.T., Craig, R.G., Syed, S.A. \& Adams, E.R. (1987) Dentin 'filtration' reduces the cytotoxic effects of setting composites in vitro. Journal of Dental Research, 66(SI), 287, (Abstract No. 1444).

Hanks, C.T., Craig, R.G., Makinen, P.K. \& Pashley, D.H. (1989) Characterization of the in vitro pulp chamber using the cytotoxicity of phenol. Journal of Oral Pathology, 18, 97.

Hanks, C.T., Diehl, M.L., Craig, R.G., Makinen, P.-K. \& Pashley, D.H. (1989) Characterization of the 'in vitro pulp chamber' using the cytotoxicity of phenol. Journal of Oral Pathology and Medicine, 18, 97.

Hanks, C.T., Strawn, S.E., Wataha, J.C. \& Craig, R.G. (1991) Cytotoxic effects of resin components on cultured mammalian fibroblasts. Journal of Dental Research, 70, 1450.

Hanks, C.T., Fat, J.C., Wataha, J.C. \& Corcoran, J.F. (1993) Cytotoxicity and dentin permeability of carbamide peroxide and hydrogen peroxide vital bleaching materials, in vitro. Journal of Dental Research, 72, 931.

Hanks, C.T., Wataha, J.C., Parsell, R.R., Strawn, S.E. \& Fat, J.C. (1994) Permeability of biological and synthetic molecules through dentine. Journal of Oral Rehabilitation, 21, 475.

Helgeland, K. \& Leirskar, J. (1972) A further testing of the effect of dental materials on growth and adhesion of animal cells in vitro. Scandinavian Journal of Dental Research, 80, 206.

Hensten-Pettersen, A. \& Helgeland K. (1977) Evaluation of biologic effects of dental materials using four different cell culture techniques. Scandinavian Journal of Dental Research, 85, 291.

Hodgson, E. \& Levi, P.E. (1987). A Textbook of Modern Toxicology. Elsevier, New York.

Hume, W.R. (1984) An analysis of the release and the diffusion through dentine of eugenol from zinc oxide-eugenol mixtures. Journal of Dental Research, 63, 881. 
Hume, W.R. \& Mount, G.J. (1988) In vitro studies on the potential for pulpal cytotoxicity of glass ionomer cements. Journal of Dental Research, 67, 915.

Kaga, M., Seale, N.S., Hanawa, T., Ferracane, J.L. \& Okabe, T. (1988) Cytotoxicity of amalgams. Journal of Dental Research, 67, 1221.

Kawahara, H., Yamagami, A. \& Nakamura, M. (1968) Biological testing of dental materials by means of cell culture. International Dental Journal, 18, 443.

LEIRSKAR, J. (1974) On the mechanisms of cytotoxicity of silver and copper amalgams in a cell culture system. Scandinavian Journal of Dental Research, 82, 74.

Leirskar, J. \& Helgeland, K. (1981) Mechanisms of toxicity of dental materials. International Dental Journal, 14, 42.

Li, Y., Noblitt, T., Stookey, K., Dunipace, A. \& Stookey, G. (1992) Cytotoxicity of silicate and ZOE cements through human dentine. Journal of Dental Research, 71(SI), 227, (Abstract No. 969).

Magos, L. (1981) Synergism and antagonism in metal toxicology. In: ed. D.F. Williams, Systemic Aspects of Biocompatibility, Vol. 1, Pp. 87-100. CRC Press, Boca Raton.

Meryon, S.D. \& Riches, D.W.H. (1982) A comparison of the in vitro cytotoxicity of four restorative materials assessed by changes in enzyme levels in two cell types. Journal of Biomedical Materials Research, 16, 519.

Muör, I.A., Hensten-Pettersen, A. \& Skogedal, O. (1977) Biologic evaluation of filling materials. A comparison of results using cell culture techniques, implantation tests and pulp studies. International Dental Journal, 27, 124.

Müller, J., Bruckner, G., Kraft, E. \& Hörz, W. (1990) Reaction of cultured pulp cells to eight different cements based on glass ionomers. Dental Materials, 6, 172.

Okabe, T., Ferracane, J., Cooper, C., Matsumoto, H. \& Wagner, M. (1987) Dissolution of mercury from amalgam into saline solution. Journal of Dental Research, 66, 33.

Pashley, D.H. (1985) Dentine-predentine complex and its permeability: a physiologic overview. Journal of Dental Research, 64, 613.

Schamlz, G. \& V. Gymnich, L. (1993) A simple dentine barrier test: cytotoxicity of dental cements. Journal of Dental Research, 72(SI), 367 (Abstract. No. 2111).

SPÅNGBERG, L. (1978) Correlation of in vivo and in vitro screening tests. Endodontics, 4, 296.

TYAS, M.J. (1977) A method for the in vitro toxicity testing of dental restorative materials. Journal of Dental Research, 56, 1284.

Wataha, J.C., Hanks, C.T. \& Craig, R.G. (1991) The in vitro effect of metal cations on eukaryotic cell metabolism. Journal of Biomedical Materials Research, 25, 1133.

WATAha, J.C., HANKs, C.T. \& CRAig, R.G. (1992) In vitro synergistic, antagonistic, and duration of exposure effects of metal cations on eukaryotic cells. Journal of Biomedical Materials Research, 26, 1297. 
This document is a scanned copy of a printed document. No warranty is given about the accuracy of the copy. Users should refer to the original published version of the material. 